\title{
The Finite Element Analysis and Optimization Design for Advancing Beam of Drilling Jumbo
}

\author{
Cong Liu ${ }^{1, a}$ and Feng Ding ${ }^{1, b^{*}}$ \\ 'Department of Mechanical and Electronic Engineering, Xi'an Technological University, Xi'an, China \\ aliu_c_107@163.com, bdfeng@xatu.edu.cn
}

Keywords: Drilling jumbo; Advancing beam; Statics analysis; Modal analysis; Optimization design

\begin{abstract}
Full hydraulic drilling jumbo plays extremely important role in tunnel construction. Drilling jumbo works in harsh environment, and the fatigue damages of advancing beam parts are easily produced. Therefore, it is necessary to analyze and study on the loading condition of the advancing beam. In this paper, the three-dimensional model of advancing beam is established by Pro/E and imported into ANSYS Workbench. The static and modal analysis are performed, and then a new kind of advancing beam structure is proposed. The new structure can enhance the dynamic and static stiffness of advancing beam, and improve the reliability and stability of jumbo. It provides a theoretical foundation for improving and optimizing the performance of the whole drilling jumbo.
\end{abstract}

\section{Introduction}

Drilling jumbo is necessary engineering equipment of the drilling and blasting method for tunnel construction [1]. The jumbo mainly has two basic functions, including drilling hole and drilling anchor holes, which can move and support multiple drill work at the same time [2,3]. Jumbo is used to propel a drilling machine on the advancing beam to complete drilling equipment. The advancing beam as the drilling machine forward and backward support member, it is important in the drilling hole shape, position and angle [4,5]. The drilling rig works in mine and tunnel, its advancing beam mostly adopts Aluminum Alloy material. In order to enhance drilling arm dynamic and static stiffness, we need to analyze static and modal analysis of the advancing beam.

Taking a tunnel drilling rig as an example, the advancing beam structure model is established by the Pro/E software and used ANSYS Workbench to analysis. The Block Lanczos algorithm is used to extract the frequency and vibration parameters of the advancing beam, for determining the vibration characteristics [6,7]. In order to enhance the life and stability of advancing beam, the structural improvements of advancing beam is proposed.

\section{The Establishment of Advancing Beam Model}

$\mathrm{PRO} / \mathrm{E}$ 3D design software is used to establish the three-dimensional structure model of the advancing beam. The three-dimensional model is converted into IGS document format, which is introduced into Workbench ANSYS for finite element analysis, as shown in Fig. 1.

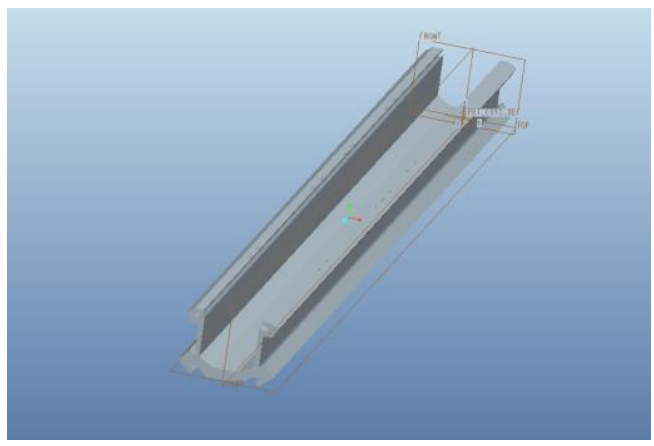

Figure 1. Three dimensional model of the advancing beam 


\section{Static Analysis of the Advancing Beam}

The static analysis can be used to calculate the influence of the fixed inertial load on the structure, and the time varying load which can be similar to the equivalent static load [8]. In classical mechanics theory, the general equation of the dynamics of the object is.

$$
[M] u^{\prime \prime}+[C] u^{\prime}+[K]=\{F(t)\}
$$

$[M]$ denote the mass matrix, $[C]$ is damping matrix, $[K]$ represent stiffness coefficient matrix, $u$ is displacement vector, $\{F(t)\}$ is force vector. In the linear static structure analysis, the force is independent of the time.

Material Selection. According to the actual jumbo working environment and its bearing capacity requirements, advancing beam needs to meet the quality of light, high strength and good rigidity requirements. So the choice of materials is Aluminum Alloy LY12CZ. Table 1 is Material properties.

Table 1 Material properties

\begin{tabular}{cccc}
\hline Material & Modulus of elasticity[GPa $]$ & Poisson ratio & Density $\left[\mathrm{kg} \cdot \mathrm{m}^{-3}\right]$ \\
\hline LY12CZ & 73.715 & 0.28 & 2700 \\
\hline
\end{tabular}

Meshing. Using Hex Dominant, it forms a hexahedral mesh in the outer layer, in the heart filled tetrahedral mesh [9]. In this way, not only ensures the accuracy of the analysis but also improves the computational efficiency. Thus we chose to use the dominant mode to promote the hexahedral mesh for advancing beam. The meshing is shown in Fig. 2.

Constraint and Load Application. In the actual installation of jumbo, the saddle of advancing beam is fixedly connected with drilling arm, so we must apply the fixed support on the saddle. The jumbo advancing beam load mainly includes: the role in promoting the hydraulic pressure on the saddle, rod holder role in advancing beam pressure and the pressure on the two end face of the propeller is $1500 \mathrm{~N}, 100 \mathrm{~N}$ and $15000 \mathrm{~N}$, respectively. The supports and loads imposed on the model are shown in Fig. 3.

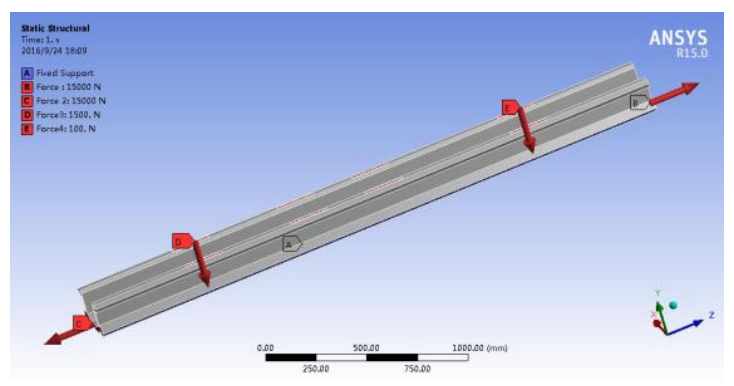

Figure 2. The advancing beam meshing

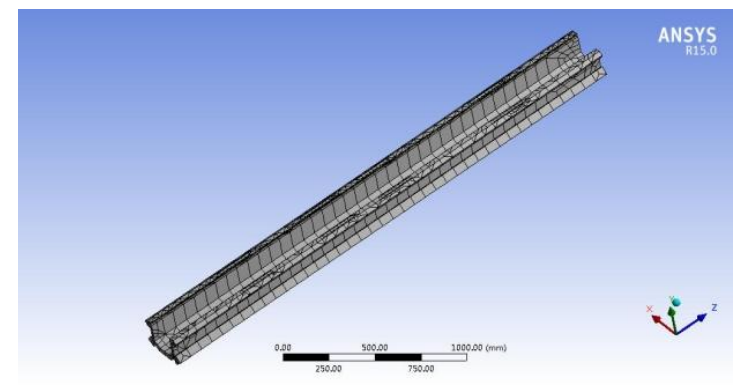

Figure 3. Supports and loads imposed on the model

Static Strength Analysis. In the process of analysis with Workbench ANSYS, Equivalent Stress uses the fourth strength theory of material mechanics. It can be more close to the real situation, according to the relevant knowledge of the mechanics of materials, theoretical formula is.

$$
\sigma_{r 4}=\sqrt{\frac{1}{2}\left[\left(\sigma_{1}-\sigma_{2}\right)^{2}+\left(\sigma_{2}-\sigma_{3}\right)^{2}+\left(\sigma_{3}-\sigma_{1}\right)^{2}\right]}
$$

$\sigma_{1}$ represent the first principal stress; $\sigma_{2}$ is the second principal stress; $\sigma_{3}$ denote the third principal stress. The mechanical properties of the advancing beam are shown in Table 2. The calculating formula of allowable stress is.

$$
[\sigma]=\frac{0.5 \sigma_{a}+0.35 \sigma_{b}}{n}
$$


In the equation $n$ is the safety factor, It is taken as 1.48 according to GB3811-2008. The stress cloud of the thruster system is calculated as shown in Fig. 4.

Table 2 Mechanical properties of the advancing beam

\begin{tabular}{cccc}
\hline Parts & Material yield strength[MPa] & Tensile strength[MPa] & Allowable stress[MPa] \\
\hline Advancing beam & 275 & 425 & 193.4 \\
\hline
\end{tabular}

As shown in Fig. 4, when the force of hydraulic jumbo is $15000 \mathrm{~N}$, this time to promote the maximum stress of the advancing beam is $2.1903 \mathrm{MPa}$, far less than the allowable stress of the advancing beam $193.4 \mathrm{MPa}$, meet the strength requirements of the material. Displacement deformation of propeller is shown in Fig. 5, the maximum deformation occurs at the end of the advancing beam, and the maximum deformation is $0.0061976 \mathrm{~mm}$.

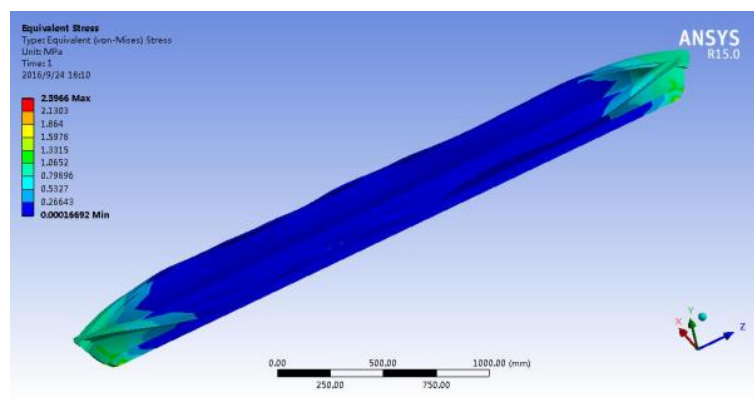

Figure 4. Equivalent stress nephogram

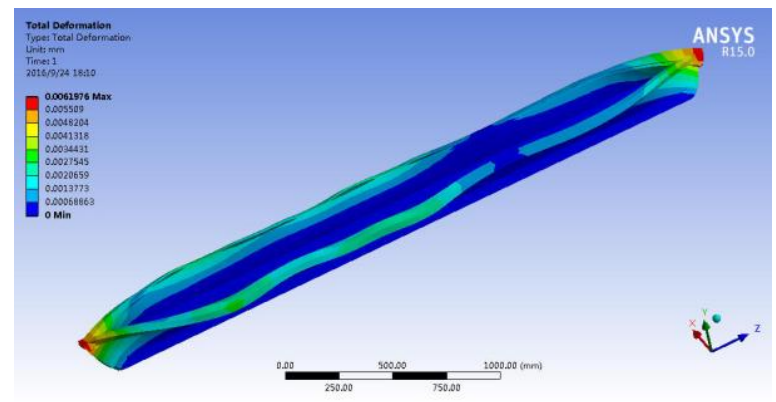

Figure 5. Equivalent elastic strain nephogram

\section{Modal Analysis of the Advancing Beam}

Modal is the natural vibration characteristics of the mechanical structure, each mode has a specific natural frequency, damping ratio and modal vibration mode [10]. The natural frequencies of each order obtained after Workbench modal analysis are shown in Fig. 6.The frequency and vibration characteristics of the first 6 modes are shown in Table 3. The impact frequency of the jumbo is $50 \mathrm{~Hz}$. It is far less than the natural frequency of the advancing beam, thus the resonance not occur.

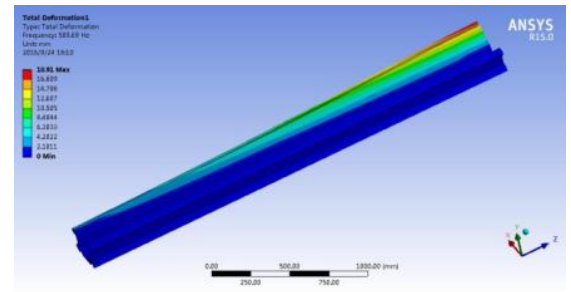

(a) Deformation-Mode 1

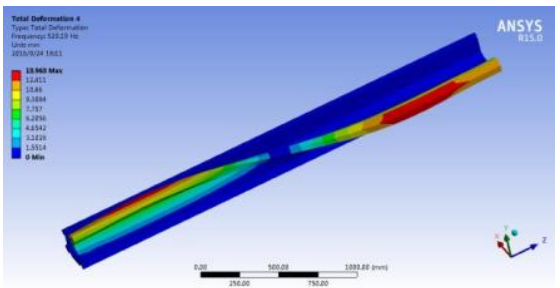

(d) Deformation-Mode 4

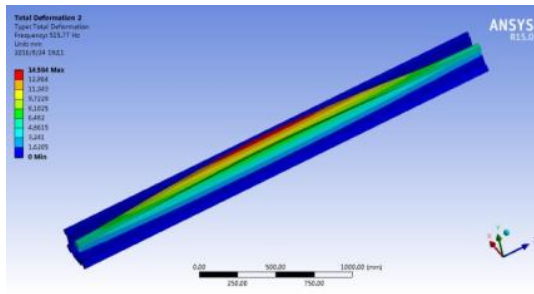

(b) Deformation-Mode 2

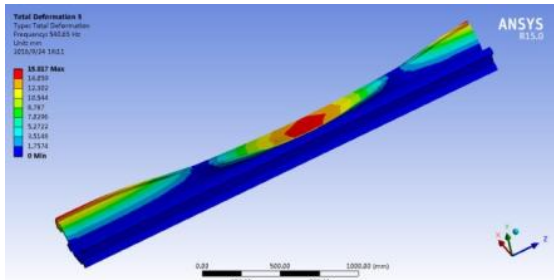

(e) Deformation-Mode 5

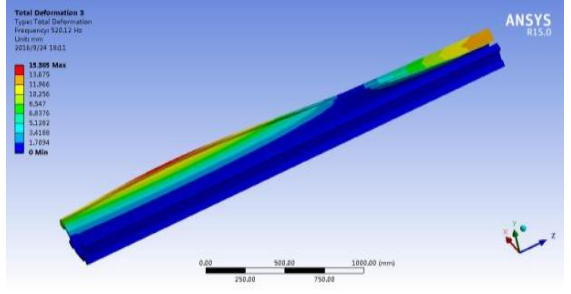

(c) Deformation-Mode 3

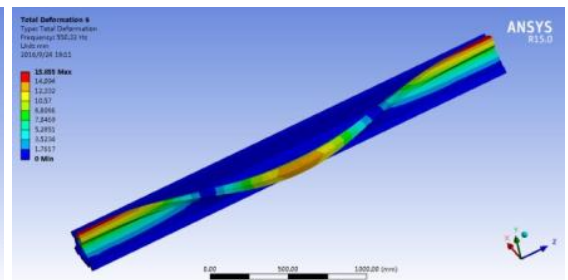

(f) Deformation-Mode 6

Figure 6. Natural frequency of each order 
Table 3 Frequency and modal analysis

\begin{tabular}{ccc}
\hline Order & Frequency[Hz] & Vibration characteristics \\
\hline 1 & 509.69 & Back part of the left stretching \\
2 & 515.77 & Middle part of the right stretching \\
3 & 520.12 & Swing around the front and back \\
4 & 529.19 & Swing around the front and back \\
5 & 540.65 & Middle part of the lift swing \\
6 & 550.32 & Middle part of the right swing \\
\hline
\end{tabular}

\section{Optimization Design of the Advancing Beam}

Optimization Design. Through the analysis, it is known that the relative displacement of the advancing beam is larger. In order to improve the dynamic, static stiffness and structural stability of the advancing beam, it is necessary to optimize the structure of the advancing beam.

The low order modal shape is mainly to the bend and torsion beam wing deformation. In order to effectively suppress advancing beam bending and torsion deformation, it will promote the beam to a closed structure. The new structure improves the advancing beam dynamic, static stiffness, and the stability of beam propulsion. The improved beam structure is shown in Fig. 7.

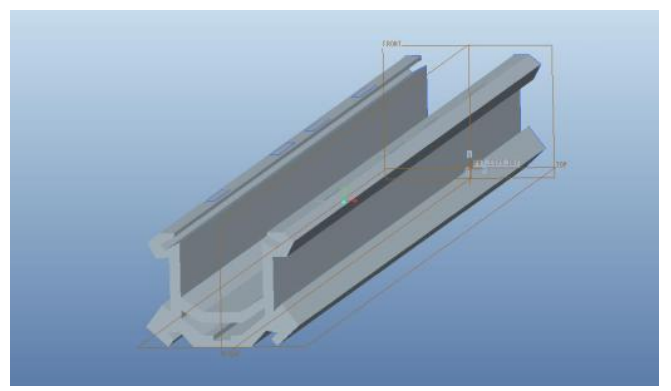

Figure 7. The improved beam structure

The Analysis of Optimization Results. The finite element dynamic modal analysis of improved beam is carried out, and the results are compared with the original beam. The results are shown in Table 4.

Table 4 Comparison of the maximum relative displacement of the advancing beam

\begin{tabular}{cccccc}
\hline State & $\begin{array}{c}\text { Maximum } \\
\text { relative } \\
\text { displacement of } \\
\text { the 1 order [mm] }\end{array}$ & $\begin{array}{c}\text { Maximum } \\
\text { relative } \\
\text { displacement of } \\
\text { the 2 order [mm] }\end{array}$ & $\begin{array}{c}\text { Maximum } \\
\text { relative } \\
\text { displacement of } \\
\text { the } 3 \text { order [mm] }\end{array}$ & $\begin{array}{c}\text { Maximum } \\
\text { relative } \\
\text { displacement of } \\
\text { the 4 order [mm] }\end{array}$ & $\begin{array}{c}\text { Maximum } \\
\text { relative } \\
\text { displacement of } \\
\text { the 5 order [mm] }\end{array}$ \\
\hline $\begin{array}{c}\text { Before } \\
\text { improvement }\end{array}$ & 18.91 & 14.584 & 15.385 & 13.963 & 15.817 \\
$\begin{array}{c}\text { After } \\
\text { improvement }\end{array}$ & 16.245 & 13.196 & 13.85 & 11.275 & 12.983 \\
\hline
\end{tabular}

The first five order maximum relative displacement is reduced by about $10 \%-19 \%$, The position error of rob can be decreased. Meanwhile the stiffness and stability of advancing beam can also be enhanced. 


\section{Conclusions}

In this paper, the static and modal characteristics of advancing beam are investigated. The PRO/E software is used to build the model, and the finite element analysis of the advancing beam is carried out by Workbench ANSYS. Through the analysis, it is known that the relative displacement of the advancing beam is larger. Therefore, the optimization and improvement of advancing beam are implemented based on the overall structure and installation position of drilling arm. The experimental results demonstrate that the improved beam can significantly improves drilling arm dynamic, static stiffness, and increase the jumbo working reliability and operation stability.

\section{Acknowledgements}

This research is financially supported by the National Science Foundation of China (grant no. 51275374) and the Fund Project of Science \& Technology on Reliability \& Environmental Engineering Key Laboratory.

\section{References}

[1] Y. Guo, Q.H. He and J.X. Zhu: The Development of Rock Drilling Robot, Modern Tunnelling Technology, (2002) No.4, p.10, (In Chinese).

[2] H.S. Wang, Q.H. He and C.P. Deng: Development and Prospect of Automatic Control System of Drill Rig, Measurement \& Control Technology, (2007) No.3, p.1, (In Chinese).

[3] R. Tan, Q.G. Cheng and H.Q. Zhao: Double-Boom Tunneling Drill Rig, Rock Drilling Machinery \& Pneumatic Tools, (2016) No.1,p.21, (In Chinese).

[4] J.F. Zhang, X.S. Hao and L. Song: Discussion on Construction Technologies for Land Section of Xiamen Second West Passage, Tunnel Construction, (2016) No.8, p.983, (In Chinese).

[5] X.H. Xie: Research on Control System of Tunnel Rock-Drilling Robot and Analyzing \&Compensating of Its Positioning Error (Ph.D., Central South University, China 2009), (In Chinese).

[6] Y.Y. Zhang, C.S. Xu: Modal Analysis of Bridge Rrane Structure Based on ANSYS, China Water Transport, (2007) No.10, p.108, (In Chinese).

[7] Y. Zhang: ANSYS Workbench 15.0 Finite Element Analysis from Entry to Master (China Machine Press, China 2014) , p.207.

[8] Y.M. Zhang: Connotation and Development of Mechanical Reliability-based Design, Journal of Mechanical Engineering, (2010) No.14, p.167, (In Chinese).

[9] S.L. Xia, J.W. He: Research of the FEM Mesh Generation Based on the Engineering Application, Aircraft Design, (2008) No.4, p.10, (In Chinese).

[10] Justin Murin, Mehdi Aminbaghai, Juraj Hrabovsky, Roman Gogola and Stephan Kugler: Beam Finite Element for Modal Analysis of FGM Structures, Engineering Structures, (2016) No.4, p.42. 